\title{
Kırsal Alanlarda SYM Üretiminde Filtreleme Yöntemlerinin Performans Analizi: Hava LiDAR Uygulaması; İstanbul Örneği
}

\author{
Mehmet DOĞRULUK ${ }^{1 *}$, Cevdet Coşkun AYDIN² ${ }^{2}$, Mustafa YANALAK ${ }^{3}$ \\ ${ }^{1}$ Hacettepe Üniversitesi, Başkent OSB TMBYO, Harita ve Kadastro Programı, Ankara \\ (mehmet.dogruluk@ hacettepe.edu.tr) ORCID ID 0000 - 0001-6698-651X \\ ${ }^{2}$ Hacettepe Üniversitesi, Mühendislik Fakültesi, Geomatik Mühendisliği Bölümü, Ankara \\ (ceaydin@ hacettepe.edu.tr) ORCID ID 0000-0003-2064-6936 \\ ${ }^{3}$ İstanbul Teknik Üniversitesi, İnşaat Fakültesi, Geomatik Mühendisliği Bölümü, İstanbul \\ (yanalakm@itu.edu.tr) ORCID ID 0000 - $0001-6805-8768$
}

\begin{abstract}
Öz
Sayısal Yükseklik Modeli (SYM) yeryüzünün fiziksel yapısını üç boyutlu olarak temsil etmek amacıyla kullanılan matematiksel bir modeldir. SYM üretimi için kullanılacak verilerin toplanma yöntemleri, çalışma alanını büyüklüğüne ve üretilecek yüzey modelin kullanım amacına göre değişsebilmektedir. Son yıllarda uzaktan algılama teknikleri ile yüzey verilerinin toplanması sağladıkları zaman ve maliyet avantajları nedeniyle tercih edilmeye başlamıştır. Özellikle ulaşılması zor bölgeler ve yüzölçümü bakımından büyük alanlar söz konusu olduğunda 3B konum verilerinin uzaktan algılama teknikleri ile belirlenmesi tercih edilmektedir. Hava LiDAR (Light Detection and Ranging) tekniği kırsal, kentsel ve ormanlık alanlarda 3B konum verisini üretmede hızlı ve güvenilir bir uzaktan algılama teknolojisidir. Ayrıca klasik fotogrametrik yöntemlerle karşılaştırıldığında veri toplama aşamasında hava durumuna, mevsimlere ve zamana daha az bağımlıdır. Dahası, yoğun ormanlarla kaplı yüzeylerde bitki örtüsüne nüfuz ederek zemin noktalarına ulaşmada ve dolayısıyla SYM oluşturmada diğer yöntemlere göre daha iyi sonuçlar alınabilmektedir.

Bu çalışmada LiDAR verileri kullanılarak bir sayısal yüzey modeli oluşturulmuş ve yüzey üzerinde bulunan zemin dışı objelerin filtreleme işlemi gerçekleştirilmiştir. Farklı filtreleme algoritmaları kullanılarak yapılan bu işlem sonucunda, elde edilen SYM'nin düşey doğruluğu referans olarak kabul edilen bir veri seti ile kıyaslanmış ve sonuçlar istatistik olarak değerlendirilmiştir. Elde edilen sonuçlar, filtreleme algoritmalarının üretilen SYM doğruluğunu etkilediğini göstermektedir. Ayrıca filtreleme yöntemlerinin ani yükseklik değişimi olan bölgelere duyarlı olduğu ve bu bölgelerde filtreleme kaynaklı hata büyüklüklerinin arttığı gözlemlenmiştir.
\end{abstract}

Anahtar Kelimeler: sayısal yüzey modeli, sayısal yükseklik modeli, hava LiDAR, filtreleme algoritmalarl, uzaktan algılama

\section{Performance Analysis of Filtering Methods in DEM Production in Rural Areas: Air LiDAR Application in İstanbul}

\begin{abstract}
The Digital Elevation Model (DEM) is an important topographical product that is used in many engineering applications as the basis. The methods of data collection for DEM production can be varied in parallel with technological developments. Remote sensing techniques have used for gathering surface data because of the time and cost advantages in recent years. In particularly, it is preferable to determine 3D position data by remote sensing techniques for large surface areas and the areas that are difficult to reach. Air LiDAR (Light
\end{abstract}

\footnotetext{
* Sorumlu Yazar
} 
Detection and Ranging) technology is a fast and reliable technique for generating 3D position data in rural, urban, and forested areas. Also when it compared with classical photogrammetric methods, it has advantages to be less dependent on weather, season and time during the data collection phase. Moreover, the technique has better results than the other methods creating DEM by penetrating into the vegetation cover on dense forested surfaces and reaching the ground spots.

In this study, a digital surface model (DSM) was produced by using LiDAR data and filtering process was performed for the objects on the surface outside the ground. As a result, different filtering algorithms were used and at the end of the process, the vertical accuracy of the obtained DEM was compared with a dataset considered as a reference and the results were evaluated statistically. It has been concluded that the filtering algorithms affected the accuracy of the generated SYM directly. Furthermore, it has been observed that the filtering methods are sensitive to regions with sudden change in height, and that the filtering error sizes increase in these regions.

Keywords: digital surface model, digital elevation model, air LiDAR, filtering algorithms, remote sensing

\section{GİRIŞ}

Yeryüzünde herhangi bir noktanın 3B konumu, uzaktan algilama teknikleri ile üretilebilen sonuç ürünlerden biridir. Özellikle ulaşılması zor bölgeler ve kapladıkları yüzölçümü bakımından büyük alanlar söz konusu olduğunda $3 \mathrm{~B}$ konum verilerinin uzaktan algılama teknikleri ile toplanması tercih edilmektedir. Hava LiDAR teknolojisi, 1990'larda ortaya çıkan ve topografik uygulamalar için geliştirilen bir uzaktan algilama sistemidir (Jones, Brewer, Johnstone, \& Macklin, 2007). Hava aracinda bulunan lazer tarama ekipmanı, belirli bir mesafedeki hedefin uzaklığını veya üç boyutlu koordinatlarını $(\mathrm{x}, \mathrm{y}, \mathrm{z})$ hesaplamak için lazer pulsunun gönderilişiyle hedeften yansıyarak kaynağa ulaşması arasındaki zaman farkını kullanılır. Lazer pulsunun gönderildiği andaki pozisyonu (konumu ve dönüklüğü) ve 1 şı hızı ile ölçeklendirilmiş uzaklık yardımıyla hedef koordinatları $(\mathrm{x}, \mathrm{y}, \mathrm{z})$ elde edilebilmektedir (Kilian, Haala, \& Englich, 1996; Liu, 2008).

LiDAR teknolojisi dünya çapında 2000'li yılların başlarından bu yana çeşitli uygulamalarda kullanılmasına rağmen, Türkiye'deki harita ve yüzey modeli üretimine yönelik çalışmalar son birkaç yıl içinde yaygınlaşmaya başlamıştır. Ancak, LiDAR nokta bulutunun kullanımı, maliyetinin yüksek olması nedeniyle çoğu durumda tercih edilememektedir. LiDAR teknolojisi ile üretilen 3B nokta bulutlarının alternatifi olarak optik sensörlerden elde edilen ve üst üste bindirilmiş görüntüler ile çok yoğun nokta bulutu verileri oluşturulabilmektedir (Serifoglu, Gungor, \& Yilmaz, 2016). Bindirmeli optik görüntüler, uçaklara yerleştirilen kameralar yardımıyla elde edilebildiği gibi insansız hava araçları ve uydu sistemleri üzerindeki sensörler sayesinde de elde edilebilmektedir. Yapılan birçok çalışmada LiDAR verilerinden üretilen yüzey modelleri ile stereo optik görüntülerden fotogrametrik yöntemlerle üretilen yüzey modellerinin doğruluğu karşılaştırılmıştır (Hobi \& Ginzler, 2012; F. Hu, Gao, Li, \& Li, 2016; Oh \& Lee, 2016; Poli, Remondino, Angiuli, \& Agugiaro, 2015; Poli \& Soille, 2012; Sefercik, Alkan, Buyuksalih, \& Jacobsen, 2013; Toutin, Schmitt, Wang, \& Reinartz, 2012). LiDAR verileri ile üretilen yüzey modelleri, LiDAR sisteminin yapısal özelikleri (çoklu dönüş) nedeniyle, özellikle yoğun ormanlık alanlarda arazi üzerindeki detay noktalarının tespitinde daha iyi sonuçlar vermektedir. Ayrıca veri toplama aşamasında mevsimsel etkilerden ve Güneşin pozisyonundan (eğim açısına) bağımsız olarak ve hava koşullarına daha az bağımlı olarak ölçüm yapılabilmesi LiDAR teknolojisinin avantajları arasında yer almaktadır (Kraus \& Pfeifer, 1998; Meng, Wang, Silván-Cárdenas, \& Currit, 2009; Yan, Shaker, \& El-Ashmawy, 2015).

Sayısal yükseklik modeli (SYM/DEM), hava LiDAR sistemleri ile toplanan 3B noktalar bir araya getirilerek elde edilebilmektedir. Yeryüzünün çıplak yüzeyini üç boyutlu olarak temsil eden bu modeli üretmek için, LiDAR sistemi ile toplanan tüm veriler içerisinden yüzey noktalarının ve yüzeye ait olmayan noktaların birbirinden ayrilması gerekmektedir. LIDAR sensörleri, yeryüzü 
objelerine ait verilerin sınıflandırılması için teorik olarak yalnızca yükseklik ve bir yoğunluk bandı kaydetmektedir. Bu sinırlı özellikler ile nokta tabanlı sinıflandırma yapmak oldukça zordur. Yüzeyin morfolojik özelliklerini kullanarak filtreleme yapan birçok algoritma geliştirilmesine karşın yüzey ve yüzeye ait olmayan noktaların birbirinden ayırılmasında bir takım belirsizlikler oluşabilmektedir. $\mathrm{Bu}$ nedenle LiDAR sisteminin dönüşleri arasındaki yükseklik farkı gibi ek özellikleri veya çalışma bölgesinin optik görüntüleri gibi yardımc1 verileri kullanan farklı filtreleme yöntemleri geliştirilmeye devam etmektedir (Chen, Gao, \& Devereux, 2017).

$\mathrm{Bu}$ çalışmanın amacı, LiDAR verilerinin filtrelenmesinde kullanılan farklı filtreleme yöntemlerinin performansını test etmektir. $\mathrm{Bu}$ çerçevede, seçilen bir test alanı üzerinde yüzeye ait olmayan zemin dışı objelerin filtrelenmesine yönelik bir uygulama gerçekleștirilmiștir. Test alanı olarak ağaç, bina ve enerji nakil hattı gibi zemin dışı objeler içeren kırsal bir bölge seçilmiştir. Ayrıca dört farklı filtreleme yöntemi ile filtrelenen 3B LiDAR nokta bulutu verileri kullanılarak dört farklı SYM oluşturulmuştur. Elde edilen SYM'lerin düşey doğruluğu, referans olarak kabul edilen bir veri seti ile kıyaslanmış ve sonuçlar istatistik olarak değerlendirilmiştir. Böylece farklı filtreleme yaklaşımlarının SYM düşey doğruluğuna etkisi araştırılmıştır. Elde edilen bulgular sonuçlar kısmında açıklanmıştır.

\section{YÖNTEM}

$\mathrm{Bu}$ çalışmada gerçekleştirilen LiDAR verilerinin filtrelenmesi ve doğruluk değerlendirilmesi süreci dört aşamalı bir iş akış1 şeklinde özetlenebilir (Şekil 1).

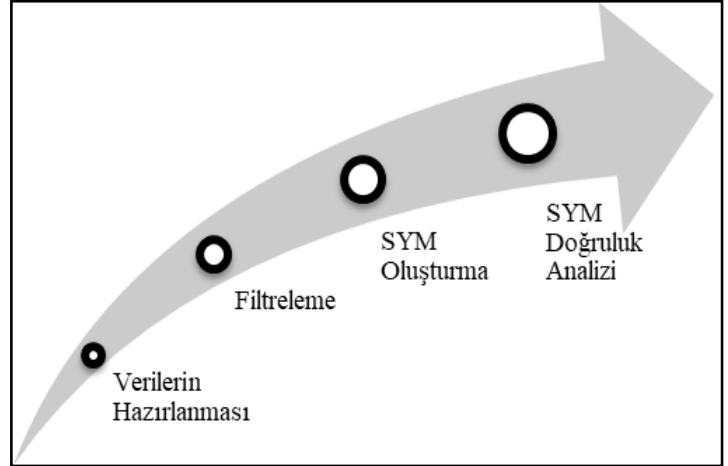

Şekil 1. Çalışmada Uygulanan Metodoloji

İlk aşama, LiDAR verilerin filtrelenme sürecine hazır hale getirilmesi için yapılan hazırlık çalışmalarını kapsamaktadır. İkinci aşama, filtreleme parametrelerinin belirlenmesi ve farklı filtreleme yöntemleri kullanılarak verilerin filtrelendiği aşamadır. Üçüncü aşamada, farklı yöntemlere göre filtrelenmiş veriler kullanılarak SYM'ler oluşturulmuştur. Ayrıca bu aşamada referans verilerden de SYM oluşturulmuştur. Son aşamada ise Referans SYM ile farklı filtreleme yöntemleri ile üretilen verilerden oluşturulmuş SYM'ler karşıllaştırılmış ve düşey doğruluk değerlendirmesi yapılmıştır. $\mathrm{Bu}$ sayede LiDAR verilerinin filtreleme performansının SYM'ler üzerindeki etkileri araştırılmıştır.

LiDAR verilerinin filtreleme işlemleri ALDPAT (Airborne LIDAR Data Processing and Analysis Tools) yazılımı kullanılarak gerçekleştirilmiştir. ALDPAT yazılımı ile ham LiDAR verilerinin birleştirilmesi, veri seyrekleştirme, verilerden yüzey oluşturma ve farklı filtreleme yöntemleri kullanılarak LiDAR verilerin filtrelenmesi işlemleri yapılabilmektedir. SYM'ler Global Mapper 18 yazılımı kullanılarak, yüzeylere ait istatistiksel hesaplamalar ise Surfer 13 yazılımı yardımıyla yapılmıştır.

\subsection{Verilerin Hazırlanması}

LiDAR nokta bulutu verilerinden SYM üretmeye başlamadan önce verilerin bazı ön işlemlerden geçirilmesi gerekmektedir. Bunlardan en önemlisi aykırı değerlerin belirlenmesidir. Çoklu yansıma ve LiDAR sistem hataları nedeniyle bazı noktalar çok 
düşük yükseklik seviyesi ile üretilmektedir. Filtreleme yöntemleri genellikle her hücredeki en alçak noktayı zemin noktası olarak kabul etmektedir. Aykırı değerlerin zemin noktası olarak kabul edilmesi büyük sapmalara yol açabilmektedir (Chen et al., 2017; Meng, Currit, \& Zhao, 2010). Bu çalışmada filtreleme işlemine başlamadan önce aykırı değer olarak tanımlanan mevcut arazi yüzeyinin çok üstünde (high point) veya altında (low point) yer alan noktalar veri setinden manuel olarak silinmiştir. Ayrıca ".las" formatındaki LiDAR veriler ".txt" formatına dönüştürülmüştür.

LiDAR verileri, İstanbul-Tuzla'da Sabanc1 Üniversitesi civarını temsil etmektedir. Çalıșma alanı (Şekil 2) yaklaşık 520m x 690m boyutlarında, genellikle alçak bitki örtüsü ile kaplı açık alanlardan oluşmakla birlikte seyrek ağaçlar, binalar ve enerji nakil hattı gibi yer üstü objeler içeren kırsal bir alan olarak tanımlanabilir.

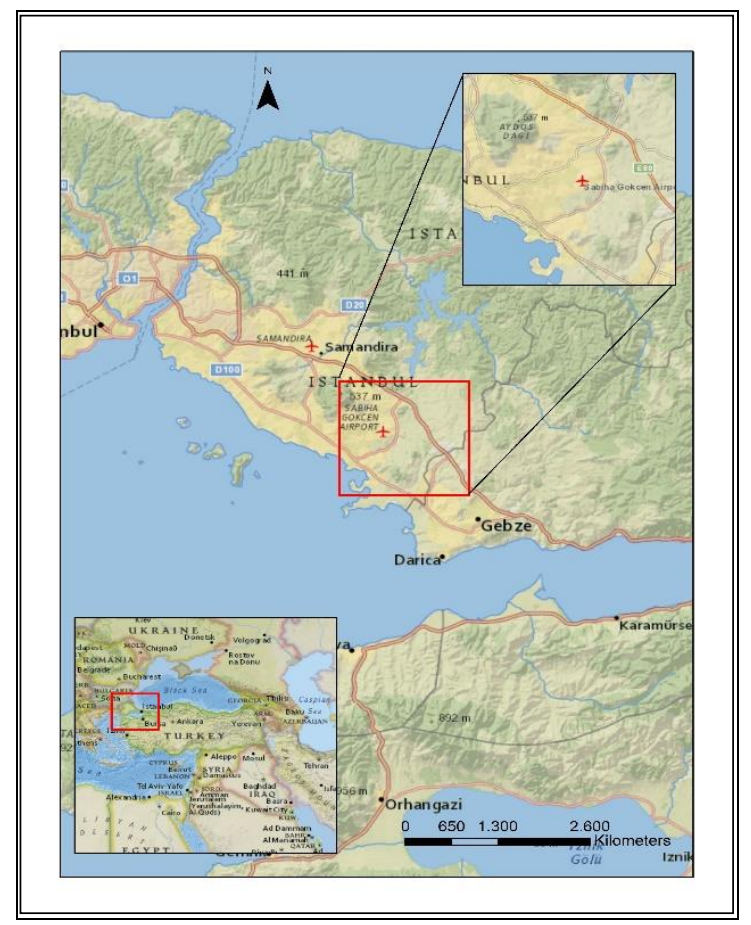

Şekil 2. Çalışmada Alanı

Çalışma alanı içerisinde yaklaşı 8.6 milyon LiDAR noktasi bulunmaktadır. Veri yoğunluğu yaklaşık 29 nokta $/ \mathrm{m}^{2}$ ye karşıl1k gelmektedir. LiDAR verileri 2012 y1lı May1s ayında ortalama $600 \mathrm{~m}$ yükseklikten Riegl Q680i model lazer tarayıc1 ile yapılan hava
LiDAR ölçümleri ile toplanmış ve Las 1.2 versiyonunda elde edilmiştir. 3B noktaların sınıflandırma işlemi Terrasolid yazılımıyla otomatik olarak gerçekleştirilmiştir.

\subsection{Filtreleme}

LiDAR verileri üç boyutlu uzaya dağılmış noktalar bütünüdür. LiDAR noktaların bir kısmı yer yüzeyini temsil eden noktalarken bir kısmı da yüzeye ait olmayan objeleri (ağaçlar, bitkiler, yapılar vb.) temsil etmektedir. Nokta sınıflandırma işlemi, her bir lazer noktasının ne tür bir cismin yansımasına karşıllk geldiğini belirleme çalışılması anlamına gelmektedir. LiDAR veri setinde yer yüzeyine ait noktaların diğer tüm noktalardan ayrılması ișlemi ise filtreleme olarak tanımlanmaktadır (Briese, 2010; Meng et al., 2010). Filtreleme işlemi yer yüzeyi ve diğer objelerin birbirinden ayrıldığı bir sınıflandırma olarak da tanımlanabilir.

Ham LiDAR nokta bulutu verilerinin filtrelenmesi, SYM üretimi için oldukça önemli bir adımdır. Birçok çalışma grubu farklı zemin filtreleme algoritmaları önermekte ve bu algoritmaları geliştirmeye yönelik çalışmalar yapmaktadır. Çoğu filtreleme yaklaşımının farklı arazi türleri üzerinde güçlü ve zayıf yönleri bulunmakla beraber filtreleme yaklaşımlanı özellikle karmaşı arazilerde hatalı sonuçlar üretebilmektedir. Ancak yine de filtrelemeye yönelik bazı genel yaklaşımlar araştırmacılar tarafından farklı arazi türleri için yaygın olarak kullanılmaktadır. Bunlardan ilki zemin noktalarının en düşük yükseklik değerine sahip olması yaklaşımıdır. Çoğu filtreleme algoritması işleme başlamadan önce veri grubunu hücrelere ayırmaktadır. Zemin noktaları bulundukları hücre içinde diğer noktalardan daha küçük yükseklik değerine sahip noktalardır. Filtrelemede kullanılan başka bir özellik eğimdir. Obje noktaları ile zemin noktaları arasındaki eğim, zemin noktalarının birbirleri arasındaki eğime göre daha büyüktür. Filtrelemede obje noktalarını ayırt etmek için eğim eşik değeri kullanılabilmekledir. Yükseklik fark1 veri filtrelemede kullanılan bir başka özelliktir. Obje noktaları ile zemin noktaları arasındaki yükseklik farkı zemin noktalarının birbirleri 
arasındaki yükseklik farkına nazaran daha büyüktür. Bildiğimiz gibi arazi yüzeyi sürekli bir yapıya sahiptir. Yüzeye ait olmayan obje noktalar1 (yapılar, bitkiler vb.) ise arazi yüzeyinin sürekliliğini bozmaktadır. $\mathrm{Bu}$ özellik de süreksizliğe neden olan zemin dişı noktalar1 belirlemede kullanılabilmektedir (Chen et al., 2017; Meng et al., 2010).

LiDAR filtreleme yöntemleri, kullandıkları algoritmalara ya da filtreleme stratejilerine göre (morfolojik, enterpolasyon tabanl, kademeli sıklaştırma tabanlı, bölümleme ve kümeleme tabanlı vb.) farklı şekillerde gruplandırılabilmektedir (Briese, 2010; $\underline{\mathrm{H} \text {. Hu }}$ et al., 2014; Sithole \& Vosselman, 2003). Bu çalışmada, ücretsiz olarak sunulan ALDPAT yazılımı yardımıla uygulanan filtreleme yöntemleri herhangi bir sinıflandırma yapılmadan aşağıda kısaca açıklanmıştır.

\subsubsection{Maksimum yerel eğim (MLS) yöntemi}

Vosselman (2000) tarafindan geliştirilen MLS (Maximum Local Slope) yöntemi bir noktanın obje noktası olup olmadığını, söz konusu nokta ile komşu noktaları arasındaki eğim değerine göre belirlemektedir (Wang \& Tseng, 2010; Keqi Zhang \& Whitman, 2005). Öncelikle bir LiDAR noktası ile bu noktanın komşuları arasındaki lokal eğim karşılaştırılır. Eğim eşik değerden daha büyük ise bu nokta obje noktas1 olarak etiketlenir. Yöntemin başarısı seçilen eğim eşik değerine ve arazinin eğimine bağlıdır. MLS yöntemi eğimin az olduğu düz arazilerde daha iyi sonuçlar vermektedir (Sithole \& Vosselman, 2004).

$\mathrm{Bu}$ çalışmada MLS yöntemi için kullanılan filtreleme parametreleri Tablo 1' de verilmiștir. Ayrıca minimum Z değeri -9999 m ve maksimum $Z$ değeri 9999 m olarak alınmıştır.

Tablo 1. MLS Yöntemi Filtreleme Parametreleri

\begin{tabular}{lllll}
\hline $\begin{array}{l}\text { Hücre } \\
\begin{array}{l}\text { Genişliği } \\
(\mathrm{m})\end{array}\end{array}$ & $\begin{array}{l}\text { Hücre } \\
\text { Yüks. } \\
(\mathrm{m})\end{array}$ & $\begin{array}{l}\text { Mak. } \\
\text { Eğim } \\
(\mathrm{m})\end{array}$ & $\begin{array}{l}\text { Min. } \\
\text { Mesafe } \\
(\mathrm{m})\end{array}$ & $\begin{array}{l}\text { Arama } \\
\text { Yarıçap1 } \\
(\mathrm{m})\end{array}$ \\
\hline 1.00 & 1.00 & 0.40 & 1 & 10 \\
\hline
\end{tabular}

\subsubsection{Genişleyen pencereler ile yükseklik eşiği (ETEW) yöntemi}

ETEW (Elevation Threshold with Expand Window) yönteminde filtreleme işlemi veri setinin kare hücrelere ayrılması ile başlar. Daha sonra her hücrelerin içerisinde yer alan noktalardan minimum yüksekliğe sahip noktalar seçilerek diğer noktalar elenir. Aynı işlem hücre boyutu arttırılarak her bir hücredeki minimum yükseklik değeri tekrardan belirlenir. Hücre içerisindeki minimum nokta yükseliği belirlendikten sonra o hücredeki diğer bütün noktalar ile minimum yüksekliğe sahip nokta arasındaki yükseklik farkı hesaplanır ve bu fark eşik değerden büyük ise o nokta zemin dışı nokta olarak sinıflandırılır. Hücre boyutu ve eşik değeri artarak devam eden bu işlem, eşik değere ulaşılıncaya veya herhangi bir nokta elenmemeye başlayıncaya kadar devam eder (K Zhang, 2007; Keqi Zhang \& Whitman, 2005).

$\mathrm{Bu}$ çalışmada ETEW yönteminde kullanılan filtreleme parametreleri Tablo 2' de verilmiştir. Minimum $Z$ değeri $-9999 \mathrm{~m}$ ve maksimum $Z$ değeri $9999 \mathrm{~m}$ alınmıştır.

Tablo 2. ETEW Yöntemi Filtreleme Parametreleri

\begin{tabular}{llll}
\hline $\begin{array}{l}\text { Hücre } \\
\begin{array}{l}\text { Genişliği } \\
(\mathrm{m})\end{array}\end{array}$ & $\begin{array}{l}\text { Hücre } \\
\text { Yüksekliği } \\
(\mathrm{m})\end{array}$ & $\begin{array}{l}\text { Eğim } \\
\text { Faktörü }\end{array}$ & $\begin{array}{l}\text { İterasyon } \\
\text { Sayı1 }\end{array}$ \\
\hline 1.00 & 1.00 & 0.30 & 10 \\
\hline
\end{tabular}

\subsubsection{Uyarlanabilen üçgenler ağı (ATIN) yöntemi}

Axelsson (2000) tarafindan geliştirilen ATIN (Adaptive Triangular Irregular Network) yönteminde filtreleme işlemi verilerin düzenli gridlere bölünmesi ile başlar. Her grid (hücre) içerisinde yer alan minimum yüksekliğe sahip noktalar seçilir. $\mathrm{Bu}$ noktalar yardımıyla Delauney üçgenlemesine göre düzensiz üçgenler ağı oluşturulur. Üçgenler ağının her üçgeninde, sınıflandırılmamış noktalar iki kritere göre zemin noktalarına eklenir: bunlardan ilki noktanın üçgen yüzeyine olan 
mesafesi, ikincisi ise noktayı üçgen yüzeyinin en yakın köşe noktası ile birleştiren çizgi ile üçgen yüzeyi arasındaki açıdır (Montealegre, Lamelas, \& de la Riva, 2015). Her bir noktanın mesafe ve açı değerleri önceden tanımlı eşik değerlerden küçük ise nokta zemin noktası olarak belirlenir. $\mathrm{Bu}$ işlem eklenebilen tüm noktalar zemin veri kümesine eklenilinceye kadar devem eder. Diğer noktalar zemin dışı nokta olarak sınıflandırılır (K Zhang, 2007).

$\mathrm{Bu}$ çalışmada ATIN yönteminde kullanılan filtreleme parametreleri Tablo 3 'de verilmiştir. Hesaplama süresini kısaltmak için, ATIN filtresi, veri setini $X$ Genişliği ve $Y$ Yüksekliği ile belirlenen küçük dikdörtgenlere böler. Bu çalışmada kullanılan $\mathrm{X}$ genişliği ve Y yüksekliği değerleri $100 \mathrm{~m}$ olarak alınmıştır. Tampon boyutu, sınıra yakın noktalarda filtreleme sonuçlarının tutarlılığını sağlamak amacıyla her küçük dikdörtgen için oluşturulan tampon mesafesidir.

Tablo 3. ATIN Yöntemi Filtreleme Parametreleri

\begin{tabular}{lllll}
\hline $\begin{array}{l}\text { Hücre } \\
\text { Boyutu }\end{array}$ & $\begin{array}{l}\mathrm{Z} \\
\text { Fark1 }\end{array}$ & $\begin{array}{l}\text { Açı } \\
\text { Eşik } \\
\text { Değeri } \\
(\mathrm{m})\end{array}$ & $\begin{array}{l}\text { Başlangıç } \\
\text { Grid } \\
\text { Boyutu } \\
(\mathrm{m})\end{array}$ & $\begin{array}{l}\text { Tampon } \\
\text { Boyutu }\end{array}$ \\
\hline 1 & $(\mathrm{~m})$ & $(\mathrm{m})$ \\
\hline
\end{tabular}

\subsubsection{Kademeli morfolojik (PM) filtreleme yöntemi}

PM (Progressive Morphological) yönteminde Keqi Zhang et al. (2003) tarafindan geliştirilen algoritma kullanılmaktadır. PM filtresi, pencere boyutunu kademeli olarak arttırarak ve farkı yükseklik eşik değerleri kullanarak farklı büyüklükteki obje noktalarını filtreleyebilir. PM algoritmasında, matematiksel morfolojide yaygin olarak kullanılan genleşme ve erozyon işlemleri kullanılmaktadır. $\mathrm{Bu}$ işlemler nesnelerin boyutunu arttırmak veya azaltmak için kullanılır. Bu algoritmada bir grid herhangi bir yükseklik değeri içermiyorsa, en yakın noktanın yükseklik değeri bu gride atanır. PM algoritmasının en önemli bileşeni olan açma işlemi grid yüzeyine uygulanır. İlk geçişte, başlangıç verileri olarak minimum yükseklik yüzeyi ve başlangıç penceresi boyutu kullanılır. Bir sonraki geçişte önceki iterasyonda üretilen süzülmüş yüzey ve artırılmış pencere boyutu kullanılır. İterasyon, filtreleme penceresinin boyutu eşik değere ulaşıncaya kadar devam eder ( $\mathrm{K}$ Zhang, 2007). PM filtresi, pencere şekline bağl1 olarak tek boyutlu (1D) veya iki boyutlu (2D) olabilmektedir. Eğer filtre penceresi bir çizgi parçasıyla tanımlanmışsa, filtre 1D iken, pencere dikdörtgen veya daire gibi 2D şeklinde ise, filtre PM 2D olarak isimlendirilmektedir (Serifoglu et al., 2016).

$\mathrm{Bu}$ çalışmada PM2D yönteminde kullanılan filtreleme parametreleri Tablo 4 'de verilmişsir.

Tablo 4. PM2D Yöntemi Filtreleme Parametreleri

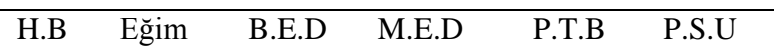

\begin{tabular}{llllll}
$(\mathrm{m})$ & & $(\mathrm{m})$ & $(\mathrm{m})$ & $(\mathrm{m})$ & \\
\hline 0.5 & 0.30 & 0.20 & 20 & 20 & 8 \\
\hline
\end{tabular}

Bu tabloda; H.B: Hücre Büyüklüğü, B.E.D: Başlangıç Eşik Değeri, M.E.D: Maksimum Eşik Değeri, P.S.U: Pencere Seri Uzunluğu olarak tanımlanmaktadır.

\subsection{SYM Oluşturma}

SYM'ler raster görüntüler veya düzensiz üçgenler ağı (TIN) olarak sunulabilir. Dağınık yapıdaki zemin noktalarının düzenli grid yapıya dönüştürülmesi için enterpolasyon uygulanması gerekmektedir (Yanalak, 2003).

$\mathrm{Bu}$ çalışmada dağınık yapıdaki LiDAR verilerinden düzenli grid yapıya geçiş sağlanarak SYM'ler üretilmiştir. Öncelikle referans verilerden SYM oluşturulmuş (Şekil 3), ardından da her bir filtreleme yöntemi ile filtrelenen verilerden dört farklı SYM üretilmiştir. Tüm SYM'ler için grid aralığı olarak $0.25 \mathrm{~m}$ seçilmiş ve bilineer enterpolasyon yöntemi kullanılmıştır. Üretilen SYM'ler yaklaşı 5.7 milyon grid noktası ile temsil edilmektedir. 


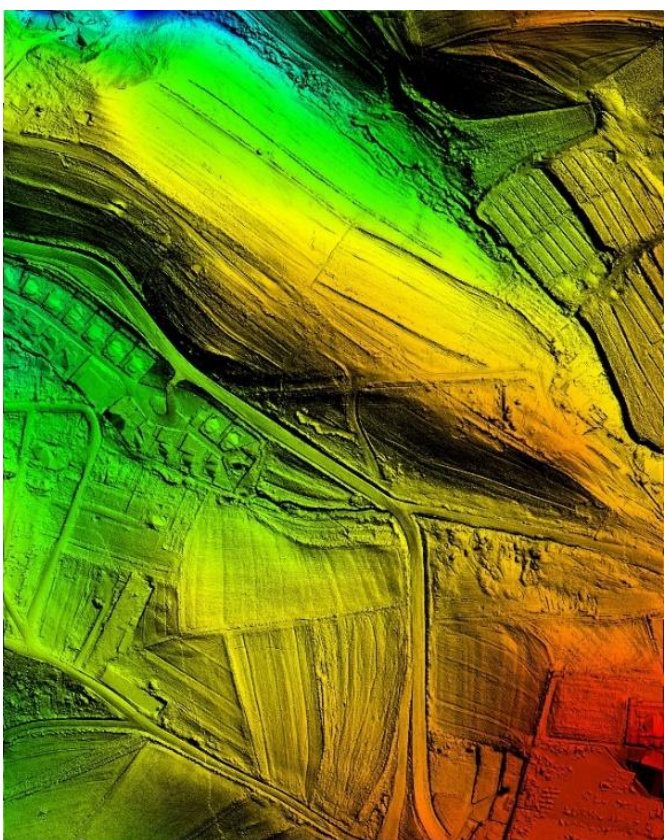

Şekil 3. Referans Verilerden Üretilen SYM

\subsection{SYM Doğruluk Analizi}

Doğruluk değerlendirmesi için öncelikle referans verilerden üretilen SYM ile dört farklı filtreleme yöntemi ile elde edilen verilerden oluşturulan SYM'ler ayrı ayrı karşılaştırılmış ve her yöntem için fark yüzeyi haritası oluşturulmuştur. Fark yüzeyi haritaları, referans yüzeydeki her bir noktanın yükseklik değerinin $\left(\mathrm{z}_{\mathrm{i}}\right)$, filtrelenmiş verilerden elde edilmiş yüzeyde aynı $\mathrm{x}$ ve $\mathrm{y}$ koordinatlarına karşılık gelen noktanın yüksekliği $\left(\mathrm{z}_{\mathrm{i}}^{\prime}\right)$ ile kıyaslanması sonucu ortaya çıkan yükseklik farklarını göstermektedir. Her bir yöntem ile elde edilen fark yüzeyi haritaları, çakışma artıklarının karesel ortalama hata $(\mathrm{KOH})$ büyüklükleri ile değerlendirilmiştir.

$\mathrm{KOH}= \pm \sqrt{\frac{1}{n} \sum_{i=1}^{n}\left(z_{i}-z_{i}^{\prime}\right)^{2}}$

Ayrica filtreleme sonucunda elde edilen çakışma artıklarının $(\Delta \mathrm{z}) \quad$ yayılımını belirlemek amacıyla her yöntem için üç farklı sinır değerine göre $(\Delta \mathrm{z}< \pm 5 \mathrm{~cm}, \Delta \mathrm{z}< \pm 10$ $\mathrm{cm}$ ve $\Delta \mathrm{z}< \pm 15 \mathrm{~cm}$ ) hata dağılımı araştırması yapılmıştır. Burada, toplam çakışma artığ1 sayısının sınır değer koşulu içinde kalan çakışma artığı sayısına bölünmesiyle koşula uygun verilerinin oransal değeri elde edilebilmektedir.

Bunlar dişında referans SYM ile filtrelenmiş verilerden elde edilen SYM'ler her bir yöntem için ayrı ayrı olmak üzere görsel olarak karşılaştırılmıştır.

\section{BULGULAR}

Dört farklı filtreleme yöntemi (MLS, ETEW, ATIN ve PM2D) kullanılarak filtrelenen LiDAR verilerinin referans verilerle kıyaslanması sonucunda ortaya çıkan çakışma artıklarına ait istatistikler Tablo 5' de gösterilmektedir.

Tablo 5. Filtreleme Sonuçları

\begin{tabular}{lllll}
\hline $\begin{array}{l}\text { Filtreleme } \\
\text { Yöntemleri }\end{array}$ & Min. & Maks. & $\begin{array}{l}\text { Ort. } \\
\text { KOH }\end{array}$ \\
\hline MLS & -5.195 & 4.140 & 0.037 & \pm 0.208 \\
ETEW & -3.212 & 3.853 & 0.027 & \pm 0.161 \\
ATIN & -4.996 & 2.735 & 0.006 & \pm 0.139 \\
PM2D & -5.699 & 3.431 & 0.020 & \pm 0.216 \\
\hline
\end{tabular}

Tablo 5'de görülen sonuçlar $\mathrm{KOH}$ bakımından değerlendirildiğinde sirasıyla $\pm 0.205 \mathrm{~m}, \pm 0.159 \mathrm{~m}, \pm 0.139 \mathrm{~m}$ ve $\pm 0.215 \mathrm{~m}$ değerleri elde edilmiştir. Buna göre, en küçük $\mathrm{KOH}$ sonuçların ATIN algoritması ile elde edildiği görülmektedir.

Farklı yöntemler ile filtrelenen verilerden oluşturulan yüzeylerin (Şekil 4) referans yüzeyle ve birbirleriyle oldukça benzer olduğu görülmektedir. Oluşturulan fark haritaları (Şekil 5) incelendiğinde ise tüm yöntemlerde hata büyüklüklerinin ani yükseklik değişimi olan bölgelerde (yapıların sinırları, çukurlar, şevler vb.) arttığ1 görülmektedir. 


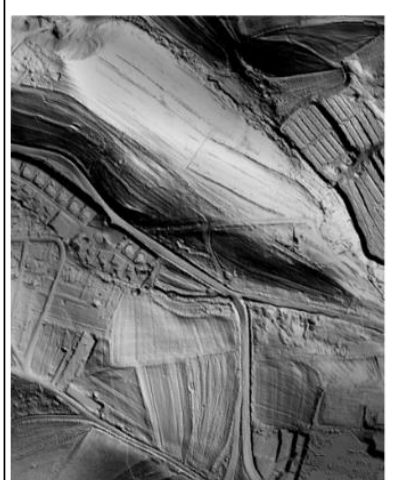

a) MLS

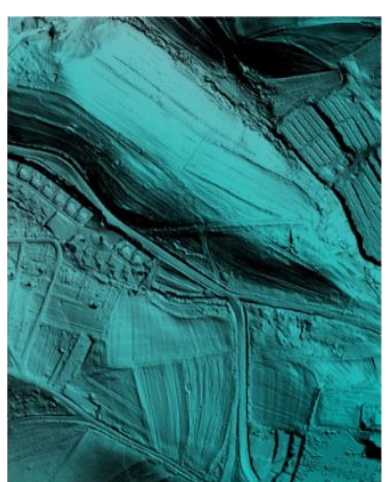

b) ETEW

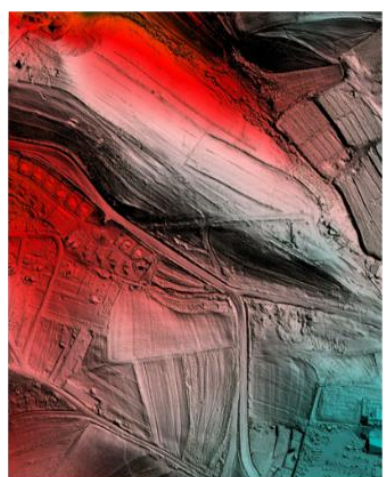

c) ATIN

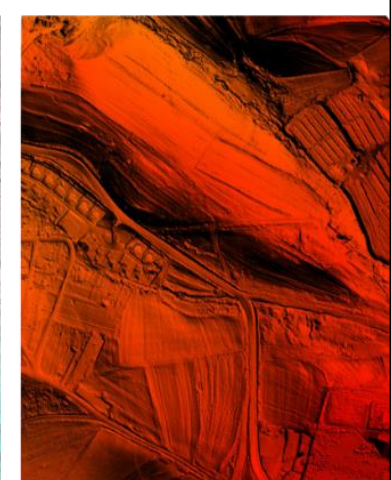

d) PM2D

Şekil 4. Filtrelenmiş verilerden Üretilen SYM'ler

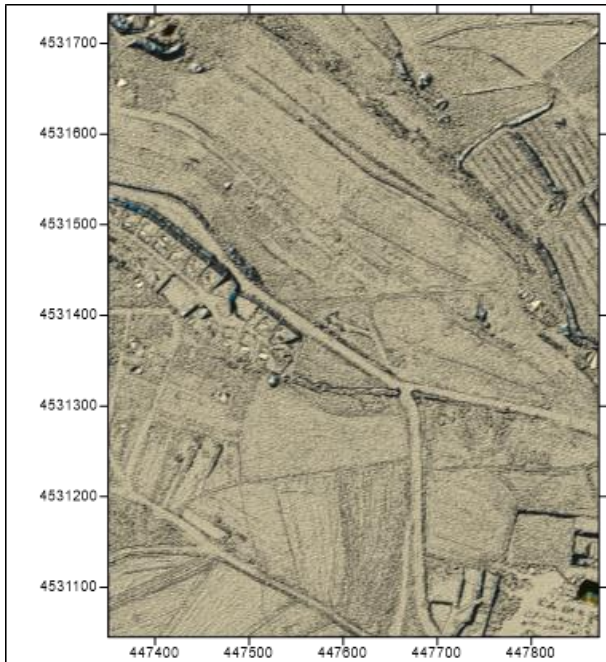

a) MLS

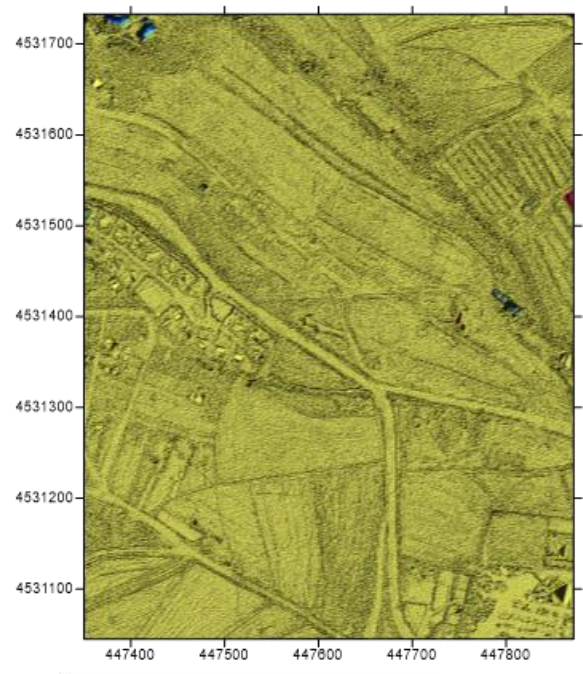

c) ATIN

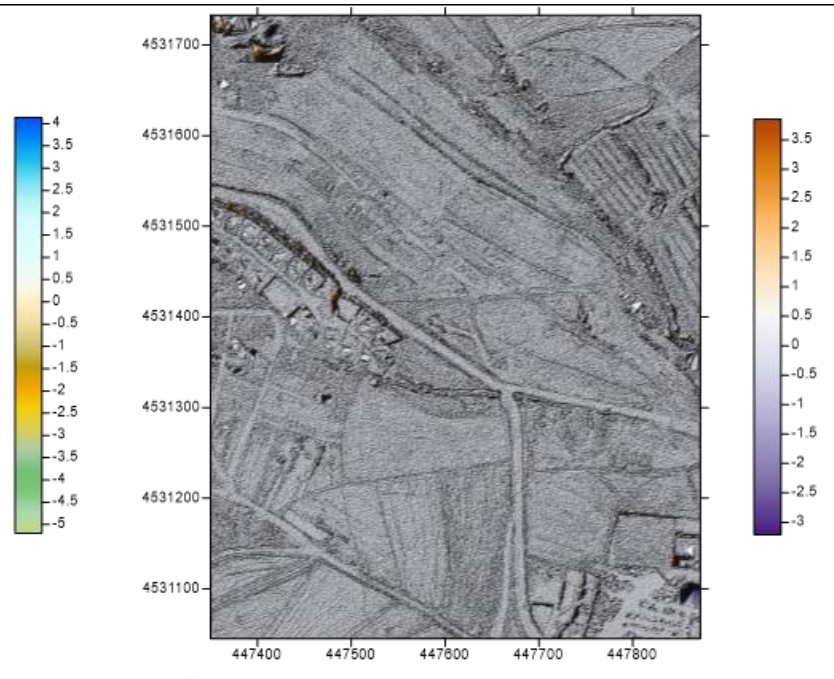

b) ETEW

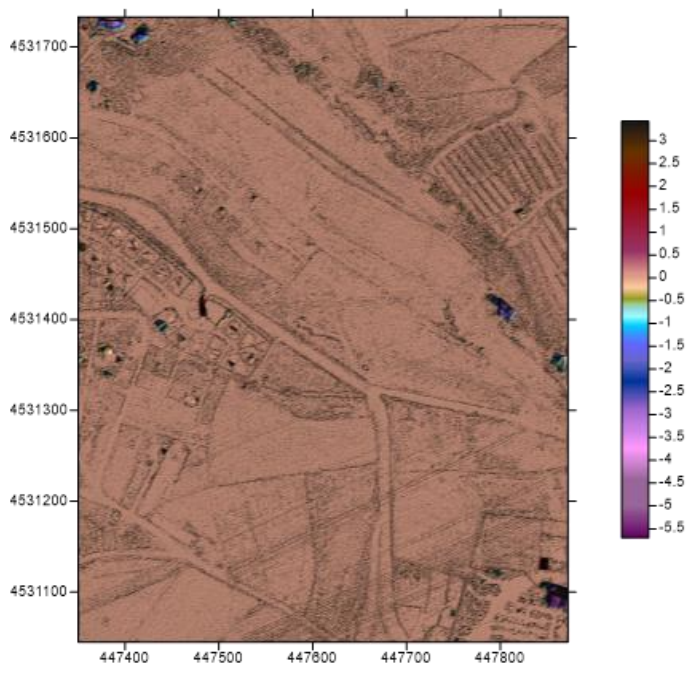

d) PM2D

Şekil 5. Referans Verilere Göre Oluşturulan Fark Haritaları [a) MLS, b) ETEW, c) ATIN, d) PM2D] 
Çakışma artıklarının $(\Delta \mathrm{z})$ hata dağılımını gösteren grafik (Şekil 6) incelendiğinde ATIN ve PM2D yöntemleri ile elde edilen çakışma artılarının \%98'inin $\pm 15 \mathrm{~cm}$ 'den daha küçük olduğu görülmektedir. Aynı koşula göre MLS yöntemi ile elde edilen çakışma artıklarının \%94'ü, ETEW yöntemi ile elde edilen çakışma artıklarının \%96'sı $\pm 15 \mathrm{~cm}$ 'den daha küçüktür. $\Delta \mathrm{z}< \pm 10 \mathrm{~cm}$ koşuluna göre, tüm yöntemlerle (MLS, ETEW, ATIN ve PM2D) sirasiyla $\% 93, \% 94, \% 96$ ve $\% 97$ oranları elde edilmiştir. $\Delta \mathrm{z}< \pm 5 \mathrm{~cm}$ koşuluna göre ise tüm yöntemlerle surasiyla $\% 86, \% 87, \% 89$ ve $\% 93$ değerleri elde edilmiştir.

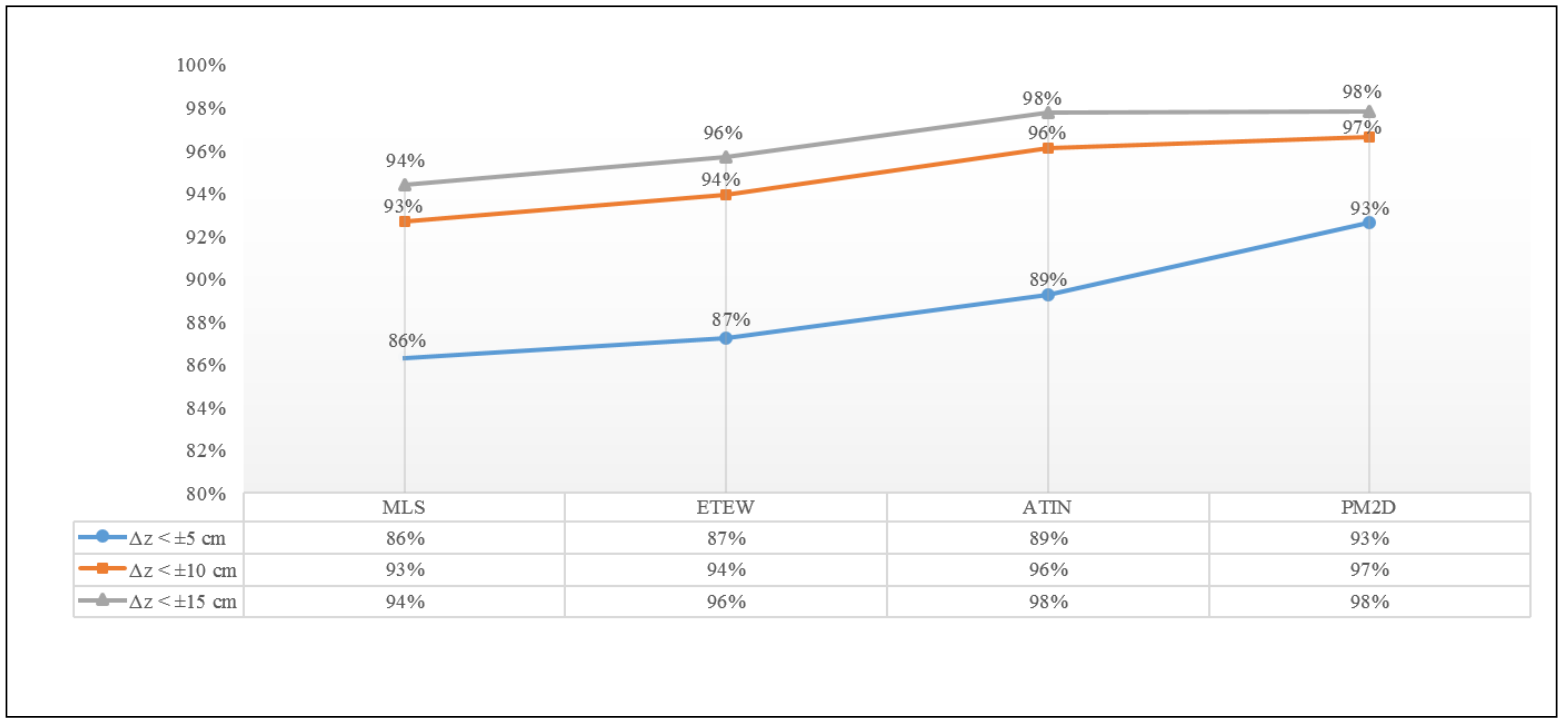

Şekil 6. Çakışma Artıklarının Farklı Büyüklükteki Hata Sınır Değerlerine Göre Oransal Dağılımı

\section{SONUÇLAR ve TARTIŞMA}

Bu çalışmada hava LiDAR ölçümleri ile elde edilen nokta bulutu verilerinin filtrelenmesi ve bu verilerden SYM oluşturma süreci ele alınmıştır. Öncelikle LiDAR verilerinin filtreleme aşamasına hazırlanması açıklanmış, filtreleme yöntemleri ve bunların çalışma prensipleri hakkında temel bilgiler verilmiştir. Ardından LiDAR verilerinin filtreleme metodolojisi için genel bir çerçeve çizilmiştir. Son bölümde farklı filtreleme yöntemleri kullanılarak filtrelenen üç boyutlu LiDAR verilerinden SYM üretimine yönelik bir uygulama gerçekleştirilmiştir. $\mathrm{Bu}$ kapsamda her bir filtreleme yöntemi (MLS, ETEW, ATIN ve PM2D) ile filtrelenen verilerden dört farklı SYM oluşturulmuştur. Yaklaşık 5.7 milyon grid noktasi ile temsil edilen her bir SYM, referans SYM ile karşılaştırılarak çakışma artıkları elde edilmiştir. Filtreleme sonuçlarının doğruluk değerlendirmesi, hem nicel hem de nitel olarak gerçekleştirilmiştir. Nicel değerlendirme, çakışma artıklarının $\mathrm{KOH}$ değerleri dikkate alınarak gerçekleştirilmiş ve ayrıca üç farklı sınır değerine göre hata dağılımı araştırması yapılmıştır. Diğer taraftan oluşturulan tüm yüzeyler referans yüzeyle görsel olarak karşılaştırılmış ve fark haritaları oluşturularak nitel değerlendirme yapılmıştır.

Filtreleme sonuçları (Tablo 5) incelendiğinde en küçük $\mathrm{KOH}$ değerinin ATIN yöntemi ile elde edildiği görülmektedir $( \pm 0.139 \mathrm{~m})$. Diğer yöntemlerle (MLS, ETEW ve PM2D) elde edilen $\mathrm{KOH}$ değerleri sirasiyla $\pm 0.205 \mathrm{~m}$, $\pm 0.159 \mathrm{~m}$ ve $\pm 0.215 \mathrm{~m}$ 'dir. ATIN yöntemi ile daha küçük $\mathrm{KOH}$ değeri elde edilmesi referans verilerin filtrelendiği Terrasolid yazılımının ATIN algoritmasina benzer bir algoritma kullanması ile açıklanabilir. Ancak yine de 
$\mathrm{KOH}$ bakımından değerlendirildiğinde, tüm filtreleme yöntemlerinin filtreleme başarısının oldukça yüksek olduğu söylenebilir. Çakışma artıklarının hata dağılımı değerlendirmesi (Şekil 6) incelendiğinde, tüm yüzeylerin 15 cm'den küçük çakışma artığı oranları \%94 ile $\% 98$ arasında değişmektedir. $\mathrm{Bu}$ sonuçlar farklı yöntemler ile filtrelenen verilerden üretilen SYM'lerin referans SYM ile oldukça yüksek oranda uyum sağladığının başka bir göstergesi olarak görülebilir. Özellikle 5 cm'den küçük çakışma artığı oranları incelendiğinde, PM2D yöntemi ile filtrelenen verilerden oluşturulan yüzeyin referans yüzeyle uyumunun diğer yöntemlere göre oldukça yüksek (\%93) olduğu görülmektedir.

Fark haritaları görsel olarak incelendiğinde (Şekil 5), referans SYM ile oldukça benzer sonuçlar alındığı söylenebilir. Ancak, çakışma $\operatorname{artığ} 1$ değerlerinin yapılara yakın bölgelerde, şevlerde ve arazinin karakteristik bölgelerinde (tümsek, çukur vb.) arttığı görülmektedir.

$\mathrm{Bu}$ çalışmada uygulanan nicel doğruluk değerlendirmesi tüm yüzey noktaları dikkate alınarak gerçekleştirilmiştir. Günümüzde benzer nitelikli çalışmalar küçük bir veri grubu kullanılarak tüm yüzeyin değerlendirilmesi şeklinde de yapılabilmektedir. Nicel doğruluk değerlendirmesinin yüzeyin tamamını oluşturan noktalar kullanılarak yapılması çoğu durumda pratik görülmemekle birlikte, küçük bir veri grubu kullanılarak yapilan değerlendirmeye göre daha kapsamlı bir analiz yapılmasına olanak sağlamaktadır. Tüm yüzeyi kapsayan bir analiz, çakışma artıklarının yüzey boyunca oransal dağılımının belirlenebilmesine ve dolayısıyla yüzeyin ne ölçüde temsil edileceğinin ölçülmesine olanak tanımaktadır. Oluşturulacak SYM'nin doğruluğu esasen bu temsil yeteneğine bağlıdır.

$\mathrm{Bu}$ çalışmada elde edilen filtreleme sonuçları bağıl bir değerlendirmeyi ifade etmektedir ve filtreleme sonuçlarının mutlak doğruluk değerlendirmesi için arazi ölçümleri ile kontrol noktası toplamak, çalışmanın sonuçlarına anlamlı katkılar sağlayacaktır. Buna ek olarak çalışma alanına ait yüksek çözünürlüklü optik görüntülerin kullanılması doğruluk analizlerinde faklı yöntemlerin kullanılmasına imkan tanıması açısından anlamlı olacaktır.

\section{KAYNAKÇA}

Axelsson, P. (2000). DEM generation from laser scanner data using adaptive TIN models. International Archives of Photogrammetry and Remote Sensing, 33(B4/1; PART 4), 111-118.

Briese, C. (2010). Extraction of digital terrain models. Airborne and terrestrial laser scanning, 135-167.

Chen, Z., Gao, B., \& Devereux, B. (2017). State-of-the-Art: DTM Generation Using Airborne LIDAR Data. Sensors, 17(1), 150.

Hobi, M. L., \& Ginzler, C. (2012). Accuracy Assessment of Digital Surface Models Based on WorldView-2 and ADS80 Stereo Remote Sensing Data. Sensors, 12(5), 6347-6368. doi:10.3390/s 120506347

Hu, F., Gao, X., Li, G., \& Li, M. (2016). DEM Extraction from Worldview-3 StereoImages and Accuracy Evaluation. International Archives of the Photogrammetry, Remote Sensing \& Spatial Information Sciences, 41.

Hu, H., Ding, Y., Zhu, Q., Wu, B., Lin, H., Du, Z., . . . Zhang, Y. (2014). An adaptive surface filter for airborne laser scanning point clouds by means of regularization and bending energy. Isprs Journal of Photogrammetry and Remote Sensing, 92(Supplement C), 98-111.

doi:https://doi.org/10.1016/j.isprsjprs.2 $\underline{014.02 .014}$

Jones, A. F., Brewer, P. A., Johnstone, E., \& Macklin, M. G. (2007). Highresolution interpretative geomorphological mapping of river valley environments using airborne LiDAR data. Earth Surface Processes and Landforms, 32(10), 1574-1592. doi:doi:10.1002/esp.1505

Kilian, J., Haala, N., \& Englich, M. (1996). Capture and evaluation of airborne laser scanner data. International Archives of Photogrammetry and Remote Sensing, 31, 383-388. 
Kraus, K., \& Pfeifer, N. (1998). Determination of terrain models in wooded areas with airborne laser scanner data. Isprs Journal of Photogrammetry and Remote Sensing, 53(4), 193-203. doi:https://doi.org/10.1016/S09242716(98)00009-4

Liu, X. (2008). Airborne LiDAR for DEM generation: some critical issues. Progress in Physical Geography, 32(1), 31-49.

Meng, X., Currit, N., \& Zhao, K. (2010). Ground filtering algorithms for airborne LiDAR data: A review of critical issues. Remote Sensing, 2(3), 833-860.

Meng, X., Wang, L., Silván-Cárdenas, J. L., \& Currit, N. (2009). A multi-directional ground filtering algorithm for airborne LIDAR. Isprs Journal of Photogrammetry and Remote Sensing, 64(1), 117-124. doi:https://doi.org/10.1016/j.isprsjprs.2 $\underline{008.09 .001}$

Montealegre, A. L., Lamelas, M. T., \& de la Riva, J. (2015). A comparison of opensource LiDAR filtering algorithms in a mediterranean forest environment. IEEE Journal of Selected Topics in Applied Earth Observations and Remote Sensing, 8(8), 4072-4085.

Oh, J., \& Lee, C. (2016). Extraction of Digital Elevation Model Using Stereo Matching with Slope-Adaptive Patch Transformation. Ksce Journal of Civil Engineering, 20(7), 2902-2909. doi:10.1007/s12205-016-1735-3

Poli, D., Remondino, F., Angiuli, E., \& Agugiaro, G. (2015). Radiometric and Geometric Evaluation of Geoeye-1, Worldview-2 And Pleiades-1a Stereo Images for 3D Information Extraction. Isprs Journal of Photogrammetry and Remote Sensing, 100, 35-47. doi:10.1016/j.isprsjprs.2014.04.007

Poli, D., \& Soille, P. (2012). Digital Surface Model Extraction and Refinement through Image Segmentation Application to the ISPRS Benchmark Stereo Dataset. Photogrammetrie Fernerkundung Geoinformation(4),
317-329.

doi:10.1127/1432-

$8364 / 2012 / 0120$

Sefercik, U. G., Alkan, M., Buyuksalih, G., \& Jacobsen, K. (2013). Generation and Validation of High-Resolution DEMs from Worldview-2 Stereo Data. Photogrammetric Record, 28(144), 362-374. doi:10.1111/phor.12038

Serifoglu, C., Gungor, O., \& Yilmaz, V. (2016). PERFORMANCE EVALUATION OF DIFFERENT GROUND FILTERING ALGORITHMS FOR UAV-BASED POINT CLOUDS. International Archives of the Photogrammetry, Remote Sensing \& Spatial Information Sciences, 41.

Sithole, G., \& Vosselman, G. (2003). Comparison of filtering algorithms. Paper presented at the Proceedings of the ISPRS working group III/3 workshop.

Sithole, G., \& Vosselman, G. (2004). Experimental comparison of filter algorithms for bare-Earth extraction from airborne laser scanning point clouds. Isprs Journal of Photogrammetry and Remote Sensing, 59(1), 85-101. doi:https://doi.org/10.1016/j.isprsjprs.2 004.05 .004

Toutin, T., Schmitt, C. V., Wang, H., \& Reinartz, P. (2012). 3D Photogrammetric Processing of Worldview-2 Data Without GCP. In M. Shortis \& N. ElSheimy (Eds.), Xxii Isprs Congress, Technical Commission I (Vol. 39-B1, pp. 277-280). Gottingen: Copernicus Gesellschaft Mbh.

Vosselman, G. (2000). Slope based filtering of laser altimetry data. International Archives of Photogrammetry and Remote Sensing, 33(B3/2; PART 3), 935-942.

Wang, C.-K., \& Tseng, Y.-H. (2010). DEM generation from airborne LiDAR data by an adaptive dual-directional slope filter: na.

Yan, W. Y., Shaker, A., \& El-Ashmawy, N. (2015). Urban land cover classification using airborne LiDAR data: A review. 
Remote Sensing of Environment, 158, 295-310.

doi:https://doi.org/10.1016/j.rse.2014.1 1.001

Yanalak, M. (2003). Effect of gridding method on digital terrain model profile data based on scattered data. Journal of Computing in Civil Engineering, 17(1), 58-67.

Zhang, K. (2007). Airborne LiDAR data processing and analysis tools. Paper presented at the AGU Fall Meeting Abstracts.

Zhang, K., Chen, S.-C., Whitman, D., Shyu, M.-L., Yan, J., \& Zhang, C. (2003). A progressive morphological filter for removing nonground measurements from airborne LIDAR data. IEEE transactions on geoscience and remote sensing, 41(4), 872-882.

Zhang, K., \& Whitman, D. (2005). Comparison of three algorithms for filtering airborne lidar data. Photogrammetric Engineering \& Remote Sensing, 71(3), 313-324. 